\title{
President's Address: A Vision of the New ASHS
}

\author{
by Cary A. Mitchell
}

Throughout the past, shortened administrative year, I have analyzed aspects of ASHS that have relevance for the future of our society. I see a society that is trying to deal with change; a society that is trying to hang on to its traditional identity while also seeking to reposition itself to remain effective and influential into the future. The dynamics of change that ASHS is facing often seem paradoxical, and it is sometimes difficult to know what direction in which to go. The future always is cloudy, and the present often is not much better because one doesn't have the benefit of perspective with which to understand what is happening. Only the past is clear, once sufficient time has lapsed to help give the all-important perspective needed for lessons learned. The trouble is, what happened in the past is not always a good predictor of what will happen in the future, since the rules of the game keep changing. However, history and trends are mainly what we have to fuel our vision, and they are better than nothing, so let's begin by reviewing some history and trends.

When I entered the professional horticultural science profession in the early 1970s, ASHS was a mature scientific society that still was growing. Accordingly, I joined the society with a sense of privilege and awe. ASHS was chugging along, happily at that point in its history, as it had been for most of the twentieth century, as a microcosm that mirrored the academic field of horticultural science in the United States. The core membership of the society was composed mainly of university faculty, mostly from land-grant institutions, who were overwhelmingly Caucasian males. Graduate students reported their thesis research at ASHS conferences and published their papers in ASHS journals because it was expected, and after graduation they, too, became members of ASHS, because that was what you did back then. Thirty years ago, Hatch federal formula funding was sufficient to conduct an applied research program, including an annual trip to a national or regional ASHS conference. Everyone in my department was an ASHS member; we were more similar than different; and life was pretty good, especially in retrospect.

Things began to change for horticulture departments around the country during the latter decades of the 20th century, and ASHS began to feel those changes as well. The good old days started to disappear. The federal government ultimately was responsible for the changes that occurred. The root cause was changing the priority of federal funding for agriculture away from formula funding and toward competitive grants. Emphasis for fundable research also shifted away from applied work supported by formula funds toward more fundamental aspects of producing crops, supported by competitive grants. Both changes were unfriendly to traditional horticulture faculty, who were neither interested to abandon the applied research for which they had been trained and had been doing happily for a long time; nor were they particularly effective in competitive grantsmanship, for which they had not been formally trained. Dan Lineberger effectively spun this dilemma in the perspective of someone moving the horticultural cheese. Although some younger HORT faculty were able to make adjustments that allowed them to keep their research programs alive while Hatch funds were drying up, a strong applied/basic split in research philosophy already had become firmly ingrained in many traditional horticulturists, who were unwilling to even try to change. For others who did try, how long is one willing to subject themselves to rejection by anonymous grant panels before they begin to rationalize giving up the competitive money chase and start looking for other ways to add value and feel appreciated? For most horticultural scientists, the answer was "not long." When the game changes but the players do not or cannot change, they tend to build a moat around their castle and defend its ramparts, even though the game has gone away!

Meanwhile, university administrators across the country were realizing that, in order not to lose competitive advantage and have to play second fiddle to other institutions, they had to play the funding game according to the rules established by federal agencies. The game rules were based largely upon recommendations from high-level scientific advisory committees, on which the voice of traditional agriculture was conspicuously absent. The result was what we have seen happen to the research mission of land-grant horticulture departments over the past 15 years: retiring traditional faculty being replaced either by specialists competitive for federal funding of hot topics, or not being replaced at all. Specialist new hires typically have not been trained in horticulture per se, so we have seen an erosion of horticultural expertise in departments bearing the name "horticulture."We also have seen the term horticulture disappear from the names of consolidated, downsized departments, so at many land-grant institutions across the nation there has been a loss of horticultural identity and expertise. When specialist new hires replacing traditionalist retirees have come from the plant molecular biology field, the remaining horticulture faculty feel disenfranchised by inaccurate administrative promises that the new hires soon will be able to apply their science to horticultural species and that new horizons will open up for horticulture departments based on the release of transgenic crops to empower the industry in significant ways. This has not happened yet, and, in fact, progress in applied molecular biology is bogged down with legal concerns regarding mostly theoretical negative effects of transgenic crops on agro-ecosystems and human health. Many molecular biology specialists have not yet moved beyond the use of model systems such as Arabidopsis, and never will as long as they keep getting grants for doing what they are doing. This lack of delivered promise has caused considerable bitterness among traditional horticulture faculty, who understandably feel betrayed. This perceived failure even further widens the gap between applied horticultural scientists and fundamental plant scientists who work in horticulture departments or former horticulture departments.

ASHS also has been a victim of those dynamics in academia! We have seen the ASHS membership erode about $40 \%$ over the past 14 years. Why? Because the horticulture traditionalist generation has been retiring, and their replacements, if any, have not been joining. ASHS typically is not attractive to many fundamental plant scientists, who have multiple choices of specialty conferences to attend and journals in which to publish. One fundamental plant science faculty member of a horticulture department told me quite seriously that he doesn't find ASHS attractive or rewarding to him. He said ASHS members spend too much time socializing, giving each other awards, and reporting whole-plant research that is not relevant to his focused, 
cellular-molecular interests. I was wearing my ASHS hat at the time, and my reply was "I probably would find your favorite meeting to be way too specialized and the nonstop science even more boring, and, by the way, get a life!" Actually, there is a lot more specialization within the 45 working groups of ASHS than meets the eye, including cellular-molecular, but targeted to application. Our nonmember critic prefers to go to prestigious Gordon Conferences, which have very specific plant-science themes and are attended by invited world leaders in a cutting-edge fundamental science specialty area, typically involving model plant species rather than crop species. Those specialty conferences do have daily recreational breaks to prevent overload burnout, but are of a more informal nature than ASHS activities. ASHS annual conferences similarly feature world-class colloquia and excellent workshops sponsored by diverse working groups also attended by world leaders, but in mission-oriented, multidisciplinary applied-science fields involving intensively cultivated economic species. An ASHS annual conference has the equivalent of 30 applied mini-Gordon Conferences going on over a several-day period in the same location, the main difference being that attendance is not by invitation only! What ASHS might do differently in the future is to more aggressively market the exciting themes of its diverse technical programs among the uninformed and misinformed, but you know what? You're still never consistently going to attract basic plant scientists to a mission-oriented, applied-science society. Don't try to become what you are not! But you know what else? There will come a day, not long from now, when the scientific state of the art and funding opportunities together will beg a merger between the fundamental and applied-plant-science fields. Molecular biology, crop science, competitive marketing, and consumer demand in the high-tech world will drive the basic and applied sectors of plant science back together. The field of horticulture needs to be ready and welcoming for that day, and ASHS actually can help that happen! We need to be ready to offer reporting and rapid-publication venues for applied biotechnology contributions with intensively cultivated species of high intrinsic value. There are literally hundreds of potential economic species, many of them tropical, that could become new crops after appropriate genetic improvement. The Crop Science Society of America is looking to develop a biotechnology journal to accommodate the expected wave of applied plant biotech papers, many of them from overseas. It would be unfortunate if future new-crop biotech publications, many of which will use horticultural species, appear only in publications not associated in some way with ASHS. Yes, the Journal of the American Society for Horticultural Science already has a section devoted to applied biotechnology papers, but this availability is not widely recognized among those who seek publication venues for their leading-edge applied biotechnology work. A completely online, rapid-publication venue is another option that could be implemented quickly. This issue needs to be addressed immediately by the publications committee if ASHS journals are to remain the major financial strength of the "new ASHS" as they are for the "now ASHS"! If the new ASHS is to be a world leader for publication of cutting-edge horticultural science research, it must begin to position itself now!

The new ASHS will need a core of customers as well as members, both of whom are primary producers of new scientific horticultural information. They will be scientists who have sufficient federal or industrial funding to sustain research programs, and who seek effective publication and reporting venues. Many of them will be located in countries other than the United States. The ASHS membership already is one-third international, and this proportion should increase even further as commercial horticultural production continues to shift out of the United States to many countries overseas and around the world.

In 2000, the United States produced fruits, nuts, and vegetables worth more than $\$ 28$ billion, almost $60 \%$ of the value of the agronomic field crops also produced in the US. The big question is whether both horticultural and agronomic crop production in this country will lose additional market share to the growing number of third-world countries that are out-competing us in the global economy, even undercutting the price of produce in our own country. The reasons include favorable growing climates and cheap labor elsewhere, but also the fact that those countries are investing considerable resources in new crop and crop-improvement research, with a growing number of new-age horticultural scientists in training.

International plant scientists who work on horticulture crops have many choices of journals and conferences competing for their budgets and loyalties. Publication venues that are prestigious, rapid, and affordable will dominate long term in the international publication marketplace. The ASHS journals presently hold first place among horticultural science publications in that regard. Reporting venues such as annual conferences will have to offer programs that are intellectually stimulating to new-age horticultural scientists, that are attended by senior scientists whom the new-agers admire, and that are structured to promote effective networking with peers in other new-age horticulture departments. A challenge for the new ASHS will be to maintain that reputation and position. ASHS journals are receiving more submissions now in spite of declining ASHS membership. In the mid to late 1990s, both the Journal and HortScience declined slightly in numbers of articles submitted for publication, while HortTechnology was still struggling to get established. Total submissions varied between about 700 and 900 manuscripts per year. Projections to the end of this year show the journal recovering slowly, HortScience up sharply, and HortTechnology growing, surpassing the Journal for the first time. The totals indicate a strong, upward trend for submissions to the ASHS journals, which are anticipated to approach 1100 this year. What is responsible for upward publication trends while society membership declines? Well, for one thing, online submission and review have reduced the time between submission and acceptance from an average of 8 months before going online to an average of 2.6 months now. In fact, a recent HortTechnology paper was accepted only 8 days after submission. Many nonmember customers are beginning to submit their horticultural science findings to ASHS because of this comparative advantage. For the new ASHS to maintain or expand its competitive edge and retain its reputation for publication excellence, it must continue to adopt technical advances in electronic publication as they come online! Frequent customers of ASHS will discover the cost-effectiveness of membership over mere customership in many categories. The more and different kinds of business that those customers do with the now ASHS, the more likely that they eventually will become members of the new ASHS. The society must work hard to stay ahead of the competition in terms of membership benefits, amenities, and equivalent costs. Most publishing researchers who will be members or customers of the new ASHS will come from countries other than the United States, and many of them will be horticultural biotechnologists. I thought at one time that HORT biotechnology would be one area in which the United States would be the undisputed leader, but intellectual property and public-perception difficulties have bogged down U.S. advances in applied biotechnology. It now looks like we will lose position in that area to more aggressive countries such as China and Brazil. That is not good for certain sectors of U.S. production horticulture, but at least ASHS has a chance to provide the rapid-publication venue that new-age biotechnologists demand. Thus far in 2004, 50.5\% of the manuscripts submitted to the Journal have come from 17 countries other than the United States. The Journal is the most fundamental ASHS journal, and it looks like the prophecy is coming true that most of the fundamental horticultural science will be done elsewhere. At least it still is being published here! For HortScience, the proportion of overseas submissions has grown to more than $40 \%$, and likely will keep going up. Only HortTechnology still is overwhelmingly American, with only $13 \%$ of its submissions coming from foreign countries, at the present time. It will be extremely important for ASHS to track the proportion of foreign-to-domestic publications over the coming years, as well as whether the absolute number of articles published in ASHS journals continues to go up. ASHS truly is becoming an international society.

It is important that ASHS try to maintain a significant representation of primary producers of new horticultural science information as voting members of the society. It generally is a good idea to build upon one's strengths, and publications are ASHS' major financial strength! Working groups are ASHS' major intellectual strength, and it is important that the new ASHS be able to attract the kinds of new-age 
horticulturists who will become core leaders for our working groups and keep them progressive. I emphasize that point because ASHS is hoping to halt its membership slide by courting several new types of horticultural scientists who have not typically been members of the society before. ASHS can provide services that those horticulturists need, but most of the anticipated new customers will not contribute research articles to the Journal or to HortScience. They will be users of horticultural science information rather than producers of new scientific information, and to prevent stagnation within any scientific field, you should not shift your core membership entirely to users. It is very important for any progressive society to maintain a critical mass of producers of new scientific information. Within the field of horticulture, many of us do some of both, but there may be more of one than the other membership category in the future.

One important category of scientific user for the new ASHS will be horticulture educators who work, not in land-grant universities, but who teach horticulture or horticulture-related courses in state and community colleges across the country. It is less likely that those future customers or members of ASHS will have ongoing horticultural research programs or substantial travel budgets. There are excellent horticulture education programs and faculty at primarily teaching institutions who are not presently associated with ASHS. If ASHS wants to reach out to them, we have to provide the continuing-education services that they demand, and which are compatible with modest teaching budgets. Community and state college HORT faculty may not be able to attend many ASHS annual conferences, but they will be excellent customers for both technical and educational materials pertaining to horticultural science that they can use in the classroom. ASHS Headquarters, with help from Editor of Digital Information Resources Tim Rhodus, is working on data bases and modes of electronic delivery to future education customers that will be affordable and accommodating. Vice President for Education Elizabeth Lamb is working with ASHS Headquarters to establish email contact lists to invite such educators to participate in ASHS. I expect that working groups within the Education Division and community college faculty who already are members of ASHS also will assist with contact information as well as with program content. New ASHS education customers will be interested in articles published in HortTechnology and will contribute articles and educational colloquia proceedings to that outreach journal themselves. I also expect CDs, DVDs, and Web-based, virtual conference proceedings to be streamed, either live, delayed, or edited and transmitted on demand, to become a prominent part of the new ASHS and its following. Regardless of whether those educators become members of ASHS or remain customers, the society is looking forward to meeting the professional needs of this category of horticultural science user from now on.

As well, county and regional extension agents have similar continuing education needs requiring updates to science-based principles of horticulture to keep their clients current solving real-life horticulture problems. Former Extension Division Vice President Bill Lamont is working on a contact list to invite agents nation-wide to greater participation in ASHS. These kinds of horticultural science users also are educators-of adult clients-either homeowners or commercial practitioners.

For both educational and extension target groups, the key to success for the new ASHS will be to develop educational materials that horticultural science user customers need, and to establish an ongoing program that is self-sustaining, evolutionary, and affordable. Both efforts together will constitute a major new direction of emphasis for ASHS and will require strategic planning for program and technicalcontent development. As has been the case for researchers, beneficiaries of the new ASHS educator and outreach programs will become future contributors to program content and direction. Developing a common, Web-based forum for discussion threads and presentations that is managed by ASHS Headquarters would get dialogue started among working groups and ad hoc committees and promote this aspect of the new ASHS. Guidance will be required for those planning forums to be successful, and I suggest that division vice presidents provide that leadership as part of their divisional duties.

Yet another group that will be key to the long-term success of
ASHS are the leaders of academic units employing faculty who work with horticultural species. When I began as a new faculty member at Purdue in 1972, the heads or chairs of virtually every academic department in the country that employed horticulture faculty were members of ASHS. Several years ago, it was determined that $70 \%$ of department heads or chairs of academic horticulturists now are not members of ASHS! This is a staggering turnabout from when I started out! Why has this occurred, and what has been the impact on ASHS membership numbers? Departmental consolidation probably is one reason for it. Department heads who were not trained in horticulture probably don't think about encouraging their HORT faculty to participate in ASHS. Less perceived importance of professional memberships in general may be another contributing factor. This situation is very similar to what graduate students do or don't do regarding participation at national society meetings. If the major professor doesn't push it, graduate students don't go to conferences. However, if major professors require it, students participate, and it usually has an eye-opening, lasting effect on their career and professional-membership choices! The same is true for junior faculty. Accordingly, we have invited nonmember horticulture unit leaders to a free year of membership in ASHS to educate them about us, and have offered incentives to member and non-member leaders alike to recruit nonmember HORT faculty in their respective departments to attend an ASHS conference and to look at the society regarding their professional-development needs. In my opinion, the new ASHS must have the support of academic leadership to stabilize the academic component of its domestic membership! I call upon the Administrator's Working Group of ASHS for additional insight to this significant issue that otherwise will limit realization of the new ASHS unless this leadership issue is resolved.

There will be a new ASHS. We don't know yet how big it will be, but we suspect it will look a bit different from the old ASHS or even the now ASHS. The male-dominated old ASHS will give way to a female and ethnic-dominated new ASHS. Departments today are hiring more immigrants from foreign countries, and training many more students who are women and who are nontraditional. The Women in Horticulture Working Group pushed for greater female representation in ASHS for years, but when they saw it coming, they knew their job was done, and they disbanded. Indeed, half of the Board of Directors today is female. Should any doubt remain, the gallery of outstanding horticulture undergraduate students for 2004 is predominately female. Of the 22 best HORT students in the nation, 19 are young women. The outstanding HORT student gallery has looked pretty much like that for the past several years. Hopefully, most of those groups of talented students will go on to graduate school and become horticulture professionals. Maybe some of them even will become ASHS members. To attract students like them to the post-graduate field of science-based horticulture, it often is desirable to introduce them to horticultural science inquiry at an even earlier stage of their education. Present at the 2004 ASHS annual conference in Austin, Texas, was Amy McDonald, a high-school student from Weslaco Texas, who reported her research work with Poinsettia. Yin-Tung Wang of Texas A \& M University mentored this promising young student, who hopefully will major in horticulture in college and one day be active in the new ASHS. Unfortunately, there were no other high-school students who participated at ASHS 2004. Several dozen undergraduate students affiliated with the Association of Collegiate Branches (ACB) were present at the annual conference, most of whom came from HORT clubs at various colleges and universities. Although those student organizations are affiliated with ASHS, they were not designed specifically for college students preparing to do a masters or $\mathrm{PhD}$ degree in a specialty area of horticultural science. A poll taken at the conference indicated that only several of those undergrads planned to go on to grad school. Even fewer graduate students were present at the presidential address and business meeting of the society, and only one postdoc was in attendance. A poll of ASHS members who either are already retired or who at least will be eligible for retirement within the next 10 years constituted the overwhelming majority of the remaining attendees at the ASHS business meeting. It doesn't take a rocket scientist to figure out that ASHS might become a low-census horticultural science society but 
a substantial publishing company over the next 10 years, processing the journal articles of international producer scientists and providing continuing education services to diverse domestic user scientists. Growing customer rolls could partially offset shrinking membership rolls for ASHS.

An additional revenue stream for the new ASHS could come from a Horticultural Crop Advisor certification program that the society would administer for candidates with credentials at least equivalent to those of an Associate Degree in horticulture, pending the outcome of a market analysis to determine whether the desired outcome would justify the anticipated total resource investment by ASHS before making final commitment to such an endeavor. Such a commitment would require human as well as financial capital.

Diversity in all things will be the name of the game for the new ASHS. Down the road, I see ASHS better networked with its sister societies, including ISHS and the tri-societies. Publications will continue to be the major financial strength of ASHS, with an expanded global look. Working groups will continue to be the intellectual strength of the society, and will become even more multi-disciplinary, with horticulture still being the lynch pin. Governance may have to be streamlined somewhat to accommodate a shrinking base of volunteer workers.

Which parts of this vision of the new ASHS will be realized will depend to a large extent on the future elected and volunteer, grassroots leadership of the society. I suggest that ASHS extend the expertise of certain working groups for strategic consultation, and don't overlook the experience and wisdom of your emeriti working group. Trust and use your Headquarters staff for implementation of strategic planning whenever possible. Be willing to serve the society in appointed or elected positions. Without a rich volunteerism ethic within its membership, a vital new ASHS cannot be realized, and the now ASHS will languish and decline as a scientific society.

I would like to thank the entire ASHS Headquarters staff for their continuing service to the society, and for their cooperation and help over the past 10 months of my presidency. I especially want to thank Mike Neff, Tracy Shawn, Ruth Gaumond, and Sylvia DeMar for their help in digging out historical data and for their patience with respect to deadlines. Finally, I wish your next president, Fred S. Davies, all success in continuing the joint effort to accommodate the ongoing change that I have witnessed during my time on the Board, including the leadership of Paul Smeal, Dan Lineberger, George Wilson, then myself, and now passing on the baton to Fred. Your Board of Directors and Executive Directors are in this common effort together, trying to deal rationally with inevitable change, trying to plan thoughtfully for the future, while meeting the needs of the here and now. ASHS management and governance truly are moving targets! By electing and appointing society members having progressive ideas and an enthusiastic volunteer spirit to positions of leadership, the best days for ASHS could yet lie ahead, but there remains a lot of work to be done. My best wishes for good luck and good decisions in creating a new ASHS that works go out to all ASHS members. Thank you for the opportunity to serve! 